\title{
QUALIDADE MICROBIOLÓGICA DE LEITE CRU REFRIGERADO OBTIDO DE PROPRIEDADES RURAIS DO MUNICÍPIO DE FRUTAL-MG: COMPARAÇÃO DAS ORDENHAS MECÂNICA E MANUAL
}

\section{MICROBIOLOGICAL QUALITY OF RAW REFRIGERATED MILK OBTAINED FROM RURAL PROPERTIES OF FRUTAL/MG: COMPARISON OF MECHANICAL AND MANUAL MILKING}

\author{
Eduardo da Silva Martins ${ }^{1}$; Camila Martins Flavio de Lima ${ }^{2}$ \\ ${ }^{1}$ Universidade do Estado de Minas Gerais - UEMG - Frutal - Brasil edusmartins@yahoo.com.br \\ ${ }^{2}$ Universidade do Estado de Minas Gerais - UEMG - Frutal - Brasil camilamartinsflavio@ hotmail.com
}

\begin{abstract}
Resumo
O objetivo deste trabalho foi avaliar a qualidade microbiológica do leite cru refrigerado obtido de propriedades rurais do município de Frutal/MG, com dois tipos de ordenha (mecânica e manual). Foram feitas análises de mesófilos totais, psicrotróficos e coliformes totais e termotolerantes. Para mesófilos totais, os resultados variaram entre 7,9 $\times 10^{3}$ a 2,2 $\times 10^{5} \mathrm{UFC}_{\mathrm{mL}^{-1}}$ no leite proveniente da ordenha manual, e entre 7,9 $\times 10^{3}$ a 6,4 $\times 10^{4} \mathrm{UFC}_{\mathrm{mL}^{-1}}$ da ordenha mecânica. Na contagem de psicrotróficos, apenas a primeira coleta do leite da ordenha mecânica apresentou esse tipo de micro-organismo, com valor de 1,85 $\times 10^{2} \mathrm{UF} \mathrm{mL}^{-1}$, enquanto que na ordenha manual houve contagens na primeira e última coleta, com valores entre $2,5 \times 10^{2}$ a $1,3 \times 10^{3} \mathrm{UFC}_{\mathrm{mL}^{-1}}$. Com relação à presença de coliformes, foram verificadas contagens mais elevadas na propriedade de ordenha mecânica, na qual houve presença de coliformes totais em todas as coletas, com resultados entre 4,3 $\times 10^{2}$ a 4,6 $\times 10^{3} \mathrm{NMP} \mathrm{mL}^{-1}$. Quatro amostras apresentaram coliformes

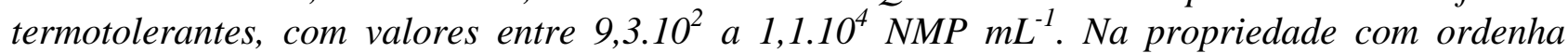
manual, houve presença de coliformes totais em duas amostras, com valores entre 9,2 $\times 10^{1}$ a 4,6 $x$ $10^{3} \mathrm{NMP} \mathrm{mL}^{-1}$, as quais também apresentaram coliformes termotolerantes, com contagens entre

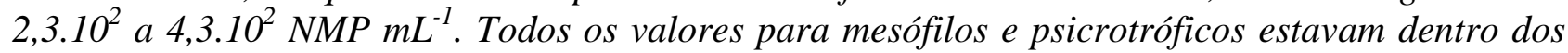
padrões exigidos pela legislação. Já para os coliformes, apesar de não haver padrão estabelecido para leite cru refrigerado, as altas contagens podem indicar deficiências nas práticas de higiene na ordenha.
\end{abstract}

Palavras-chave: qualidade microbiológica; leite cru refrigerado; ordenha mecânica; ordenha manual.

\section{Introdução}

No Brasil, a produção de leite gira em torno de 28.700 milhões de litros por ano. De acordo com a Embrapa, 21.900 milhões de vacas foram ordenhadas em 2009, ação que resultou numa produtividade na ordem de 1.307 litros por animal neste período. Minas Gerais é a maior bacia 
leiteira do país, com produção de 7,2 bilhões de litros por ano. No estado, a produção de leite se concentra nas mesorregiões do Triângulo/Alto Paranaíba, sul/sudoeste e Zona da Mata. Dentre essas bacias leiteiras, o Triângulo/Alto Paranaíba, com uma produção de mais de 1 bilhão de litros por ano, representa cerca de $22,50 \%$ do volume total produzido no estado. No sul/sudoeste de Minas, a produção é superior a 800 milhões de litros (18,52\% do total) e a Zona da Mata, com mais de 500 milhões de litros por ano, detém 12,30\% da produção (SEBRAE, 2006).

A implantação da estocagem do leite cru refrigerado na própria fazenda iniciou-se no Brasil na década de 1990, sendo regulamentada pelo Ministério da Agricultura em 2002 (BRASIL, 2002). A refrigeração do leite na propriedade reduz os custos de produção e impede a deterioração do leite por atividade acidificante de bactérias mesofílicas. Porém, pode ocasionar problemas tecnológicos associados à atividade de enzimas proteolíticas e lipolíticas de bactérias psicrotróficas. Muitas destas enzimas são termorresistentes e estão relacionadas às perdas de qualidade do leite de outros produtos lácteos (PINTO, MARTINS e VANETTI, 2006).

A qualidade do leite está associada à carga microbiana inicial contida no produto, e quanto maior o número de contaminantes e a temperatura de estocagem, menor será o tempo de conservação do produto (SILVEIRA, CARVALHO e TEIXEIRA, 1998).

A obtenção em boas condições de higiene, e o resfriamento imediato a $4{ }^{\circ} \mathrm{C}$, são medidas fundamentais e primárias para garantir a qualidade e segurança do leite e consequentemente dos seus derivados (ARCURI et al., 2006). O crescimento de bactérias no leite é reduzido por meio do resfriamento abaixo de $10{ }^{\circ} \mathrm{C}$, e temperaturas próximas de $3{ }^{\circ} \mathrm{C}$ a $4{ }^{\circ} \mathrm{C}$, atingidas de uma forma rápida, permitem que as atividades bacterianas sejam bem diminuídas (VINHOLIS, 2007).

O leite produzido no Brasil apresenta, de maneira geral, altas contagens de microorganismos, demonstrando com isso que há deficiências no sistema de produção (CERQUEIRA e LEITE, 1995). A partir dos anos 90, gradativamente, algumas cooperativas de laticínios iniciaram a implantação de programas de pagamento do leite por qualidade, tendo por base as provas de redutase, crioscopia e contagem global de micro-organismos aeróbios mesófilos (MÜLLER, 2002).

O controle microbiológico em amostras de leite é realizado principalmente através da pesquisa de micro-organismos indicadores que, quando presentes, podem fornecer informações sobre as condições sanitárias da produção, do processamento, ou armazenamento, assim como a possível presença de patógenos e estimativa da vida de prateleira do produto (TAMANINI et al., 2007).

Atualmente, a competitividade dos mercados induz o consumidor brasileiro a tornar-se mais exigente em relação à qualidade dos produtos ofertados. A indústria laticinista tem-se modernizado e exigido do produtor uma matéria-prima de melhor qualidade, na tentativa de tornase mais competitiva. Para assegurar a qualidade, foram implantadas normas nacionais de padrões de 
qualidade do leite, determinadas pelo Programa Nacional de Melhoria da Qualidade do Leite, do Ministério da Agricultura, Pecuária e Abastecimento (MAPA) (RIBEIRO e CARVALHO, 2007) e pela Instrução Normativa 51.

A versão definitiva das novas normas de produção leiteira foi publicada na Instrução Normativa $n^{\circ} 51$ (IN 51), de 18 de setembro de 2002, que determina novas normas na produção, identidade e qualidade de leites tipos A, B, C, pasteurizado e cru refrigerado, além de regulamentar a coleta de leite cru refrigerado e seu transporte a granel (BRASIL, 2002).

Diante do exposto, este trabalho teve como objetivo avaliar a qualidade microbiológica do leite cru refrigerado de duas propriedades rurais de Frutal/MG, sendo uma com ordenha mecânica e outra com ordenha manual.

\section{Material e Métodos}

\section{Coleta e preparação das amostras}

As amostras de leite cru refrigerado foram coletadas semanalmente, durante 5 semanas, em duas propriedades rurais localizadas no município de Frutal/MG, sendo uma com ordenha mecânica e outra com ordenha manual.

As amostras foram coletadas e transportadas assepticamente e colocadas em frascos esterilizados, sendo acondicionadas em caixa de material isotérmico, contendo cubos de gelo, e levadas até o laboratório de Microbiologia da Universidade do Estado de Minas Gerais (UEMG, campus de Frutal), sendo mantidas sob baixa temperatura até o momento das análises microbiológicas, as quais foram realizadas no máximo em 2 horas.

O leite foi medido assepticamente e $25 \mathrm{~mL}$ de cada amostra foram adicionados a $225 \mathrm{~mL}$ de água peptonada $0,1 \%$ esterilizada. Após homogeneização das amostras, foram preparadas as demais diluições decimais, que foram utilizadas nas análises microbiológicas.

\section{Análises microbiológicas do leite cru refrigerado}

As análises microbiológicas feitas no leite das duas propriedades estão descritas abaixo.

\section{Contagem de bactérias mesófilas}

Para a quantificação de bactérias mesófilas foram feitas as contagens padrão em placas com incubação a $35 \pm 1{ }^{\circ} \mathrm{C} / 48$ h pelo método de "pour plate”, em Ágar Padrão para Contagem (PCA), em duplicata, em diferentes diluições. Após o período de incubação, foram contadas as colônias, nas placas que apresentaram crescimento no intervalo de no mínimo 25 e no máximo 250 colônias por placa. 


\section{Contagem de bactérias psicrotróficas}

Para a quantificação de bactérias psicrotróficas foram feitas as contagens padrão em placas com incubação a $7{ }^{\circ} \mathrm{C}$, durante 10 dias, em Ágar Padrão para Contagem (PCA), em duplicata, em diferentes diluições. Após o período de incubação, foram contadas as colônias, nas placas que apresentaram crescimento no intervalo de no mínimo 25 e no máximo 250 colônias por placa.

\section{Determinação de coliformes totais e fecais}

Para a determinação do Número Mais Provável (NMP) de coliformes totais, de cada diluição $\left(10^{-1}\right.$ a $\left.10^{-3}\right)$, foram tomadas três porções de $1 \mathrm{~mL}$ cada e inoculadas, respectivamente, em três tubos contendo $9 \mathrm{~mL}$ de Caldo Verde Brilhante Bile 2\% com tubo de Durham invertido, incubando-os a $35{ }^{\circ} \mathrm{C}$, durante 24 a 48 horas. A prova foi considerada positiva somente quando se verificou turvação do meio e produção de gás nos tubos de Durham, dentro de um período de incubação máximo de 48 horas. A determinação quantitativa foi realizada de acordo com a técnica do NMP, recomendada pela American Public Health Association (1992).

Uma alçada de cada cultura foi tomada dos tubos positivos de Caldo Verde Brilhante Bile $2 \%$ e transferida para tubos de Caldo E.C, contendo tubos de Durham invertidos, e incubados a 45,5 ${ }^{\circ} \mathrm{C}$, em banho-maria com agitação, para determinação de coliformes termotolerantes. Após a incubação por 24 a 48 horas foi realizada a leitura, e os tubos que se apresentaram turvação do meio e produção de gás foram considerados positivos. Para cada diluição, o número de tubos positivos foi anotado e quantificado através da tabela de NMP, determinando, assim, o NMP de bactérias coliformes termotolerantes por $\mathrm{mL}$ de leite cru refrigerado.

\section{Resultados e discussão}

\section{Contagem de aeróbios mesófilos}

Com relação aos resultados das análises para a contagem de aeróbios mesófilos, verificou-se que a propriedade de ordenha manual apresentou valores superiores aos resultados obtidos da propriedade de ordenha mecânica, variando esses resultados entre $7,9 \times 10^{3} \mathrm{a} 4,0 \times 10^{5} \mathrm{UFC} \mathrm{mL}^{-1}$ para a manual, enquanto que a máxima contagem na ordenha mecânica esteve em $6,4 \times 10^{4}$ UFC $\mathrm{mL}^{-1}$ (Tabela 1).

O leite obtido da propriedade de ordenha mecânica funciona em circuito fechado, saindo direto da vaca pelas mangueiras do circuito e caindo direto no tanque, já sendo rapidamente resfriado, o que pode justificar a baixa contagem de aeróbios mesófilos. Já o leite obtido da propriedade de ordenha manual é deixado em latões durante o período da ordenha e só após o término dela é levado para o tanque de expansão, ficando certo período em alta temperatura, o que 
provoca a multiplicação de micro-organismos aeróbios mesófilos. Assim, os resultados obtidos podem comprovar a importância do resfriamento logo após a ordenha.

Tabela 1 - Contagem de mesófilos totais no leite cru refrigerado, das propriedades analisadas

\begin{tabular}{ccc}
\hline & \multicolumn{2}{c}{ Mesófilos totais $\left(\right.$ UFC.mL $^{\mathbf{1}}$ ) } \\
\cline { 2 - 3 } Coleta & Ordenha Mecânica & Ordenha Manual \\
& & \\
\hline 1 & $7,9.10^{3}$ & $2,1.10^{4}$ \\
2 & $2,8.10^{4}$ & $6,2.10^{4}$ \\
3 & $6,4.10^{4}$ & $4,0.10^{5}$ \\
4 & $2,3.10^{4}$ & $7,9.10^{3}$ \\
5 & $1,0.10^{4}$ & $2,2.10^{5}$ \\
& & \\
\hline Padrão & & \\
\hline
\end{tabular}

Moraes et al. (2005) testaram 12 propriedades do Estado do Rio Grande do Sul quanto ao número de bactérias mesófilas e observaram que apenas 3 ficaram dentro do valor exigido pela legislação.

Nero, Viçosa e Pereira (2009), também analisando aeróbios mesófilos em 60 propriedades da cidade de Viçosa (MG), sendo 57 de ordenha manual e apenas 3 com ordenha mecânica de balde ao pé, observaram que das 60 propriedades, 47 se encontraram com valores permitidos pela legislação, o que indica que a maioria dos produtores adota medidas higiênicas e de conservação do leite.

Silva et al. (2011), em análises de mesófilos nas regiões do Agreste de Pernambuco, obtiveram resultados em média de $8,3 \times 10^{6} \mathrm{UFC} \mathrm{ml}^{-1}$, resultados esses acima dos padrões exigidos para estes micro-organismos.

No presente trabalho, foi observado que os resultados de todas as amostras coletadas encontraram-se dentro do padrão exigido pela legislação para mesófilos totais, que atualmente é de no máximo $7,5.10^{5} \mathrm{UFC} \mathrm{mL}^{-1}$. Com base nestes resultados, fica claro que uma das medidas mais corretas para o controle desses micro-organismos é a resfriamento do leite logo após sua obtenção.

\section{Contagem de psicrotróficos}

Com relação à presença de psicrotróficos, na propriedade de ordenha mecânica apenas na $1^{\mathrm{a}}$ coleta cresceu esse tipo de micro-organismo, obtendo com valor de $1,8 \times 10^{2} \mathrm{UFC} \mathrm{mL}^{-1}$. Já na propriedade com ordenha manual, houve presença na $1^{\mathrm{a}}$ e na $5^{\mathrm{a}}$ coleta, variando esses resultados entre $2,5 \times 10^{2}$ a $1,3 \times 10^{3} \mathrm{UFC} \mathrm{mL}^{-1}$ (Tabela 2). Estes valores estão de acordo com a legislação vigente, que diz que a contagem de psicrotróficos não deve exceder a $10 \%$ o total de mesófilos da amostra. 
Também de acordo com Pinto, Martins e Vanetti. (2006), contagens de psicrotróficos a partir de $1,0 \times 10^{5} \mathrm{UFC}_{\mathrm{mL}^{-1}}$ são suficientes para causar alterações em leites e derivados, o que não foi verificado no presente trabalho.

Tabela 2 - Contagem de psicrotróficos no leite cru refrigerado, das propriedades analisadas

\begin{tabular}{ccc}
\hline & \multicolumn{2}{c}{ Psicrotróficos (UFC.mL ${ }^{-1}$ ) } \\
\cline { 2 - 3 } Coleta & Ordenha Mecânica & Ordenha Manual \\
& & \\
\hline 1 & $1,8.10^{2}$ & $1,3.10^{3}$ \\
2 & ausente & ausente \\
3 & ausente & ausente \\
4 & ausente & ausente \\
5 & ausente & $2,5.10^{2}$ \\
\hline \multicolumn{2}{c}{} \\
\hline
\end{tabular}

A refrigeração por tempo prolongado nas propriedades leiteiras pode comprometer muito a qualidade do leite cru, considerando que a refrigeração em condições inadequadas possibilita o crescimento da microbiota psicrotrófica, sendo necessários investimentos contínuos em boas práticas para prevenção da contaminação por esses micro-organismos (SANTANA, 2001).

Altas contagens de psicrotróficos em leite implicam em sérios prejuízos econômicos e tecnológicos para a indústria beneficiadora (SILVA et al., 2011). Santos (2008), analisando psicrotróficos em 40 amostras de leite cru refrigerado no estado de Goiás, observaram resultados bem superiores ao do presente estudo, obtendo resultados que ficaram entre $7,0 \times 10^{3}$ a $4,0 \times 10^{6}$ UFC $\mathrm{mL}^{-1}$, evidenciando a provável falta de higiene da ordenha e instalações. Valores bem superiores também foram encontrados por Silva et al. (2010a), analisando psicrotróficos de propriedades rurais do Sudoeste Goiano, nas quais encontraram valores de $2,2 \times 10^{5} \mathrm{UFC} \mathrm{mL}^{-1}$ para ordenha mecânica e $3,1 \times 10^{5} \mathrm{UFC} \mathrm{mL}^{-1}$ para ordenha manual.

Segundo Santos (2008), se o leite é submetido a períodos longos de refrigeração, o controle de psicrotróficos na matéria-prima pode ser mais importante do que o controle realizado após o processamento.

\section{Contagem de coliformes totais}

Quanto à presença de coliformes totais, em algumas amostras do leite cru refrigerad, proveniente das propriedades avaliadas, foi evidenciada a presença deste grupo de microorganismos. Na propriedade com ordenha mecânica, todas as amostras apresentaram contagens que variaram de $4,3 \times 10^{2}$ a 4,6 × $10^{3} \mathrm{NMP} \mathrm{mL}^{-1}$. Já na propriedade com ordenha manual, houve contagens apenas nas $2^{\mathrm{a}}$ e $3^{\mathrm{a}}$ coletas, com resultados que variaram entre $9,2 \times 10^{1}$ a $4,6 \times 10^{3} \mathrm{NMP}$ 
$\mathrm{mL}^{-1}$ (Tabela 3), ficando claro que a ordenha manual nem sempre apresenta contagens superiores à ordenha mecânica e que nem sempre é o tipo de ordenha o responsável por contaminações do leite cru. Em estudo bem semelhante, Silva et al. (2010a), também observaram que a ordenha mecânica não significou a obtenção de leite de melhor qualidade microbiológica.

Tabela 3 - Número Mais Provável de coliformes totais no leite cru refrigerado, das propriedades analisadas

\begin{tabular}{ccc}
\hline \multirow{2}{*}{ Coleta } & \multicolumn{2}{c}{ Coliformes totais (NMP.mL $\mathbf{~}^{\mathbf{1}}$ ) } \\
\cline { 2 - 3 } & Ordenha Mecânica & Ordenha Manual \\
\hline 1 & $4,6.10^{3}$ & Ausente \\
2 & $4,6.10^{3}$ & $9,2.10^{1}$ \\
3 & $4,6.10^{3}$ & $4,6.10^{3}$ \\
4 & $9,3.10^{2}$ & Ausente \\
5 & $4,3.10^{2}$ & Ausente \\
\hline \multicolumn{3}{c}{ Não estabelecido } \\
\hline
\end{tabular}

A contaminação do leite por bactérias do grupo coliformes indica a falta de higiene e sanitização do estábulo, dos colaboradores e dos animais, evidenciando a necessidade de reeducar os procedimentos adotados pelas propriedades (SILVA et al., 2010a).

Silva et al. (2011), analisando 6 propriedades leiteiras no Agreste Pernambucano, para contagens de coliformes, obtiveram contagens médias de $2,5 \times 10^{5} \mathrm{NMP} \mathrm{mL}^{-1}$. Silva et al. (2010b), também observaram contagens elevadas de coliformes em propriedades de Umuarama-PR, constatando a falta de condições para a prática leiteira. De acordo com os autores, a literatura dita que apenas contagens acima de $10^{2} \mathrm{UFC}^{-1}$ de micro-organismos do grupo coliforme indicam falhas na higiene durante e entre as ordenhas. Os coliformes são considerados indicadores de contaminação, por isso é importante implantar boas práticas durante todo o processo de obtenção do leite.

\section{Contagens de coliformes termotolerantes}

Enquanto os coliformes totais indicam contaminações do ambiente, a presença dos coliformes termotolerantes (como a Escherichia coli) indica contaminações de origem fecal (FRANCO e LANDGRAF, 2008).

Nos resultados obtidos para coliformes termotolerantes, foi verificada deficiência de condições higiênico-sanitárias na obtenção do leite, principalmente na propriedade de ordenha mecânica, que apresentou contagens de coliformes termotolerantes, com exceção da primeira coleta.

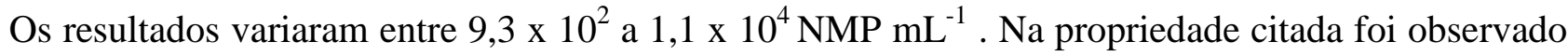


no momento da ordenha que as teteiras se arrastavam pelo chão, onde continha fezes dos animais, o que pode justificar esses resultados.

A propriedade de ordenha manual apresentou contagens na $2^{\mathrm{a}}$ e $3^{\mathrm{a}}$ coletas, com valores inferiores, entre $2,3 \times 10^{2}$ a 4,3 $\times 10^{2} \mathrm{NMP} \mathrm{mL}^{-1}$ (Tabela 4).

Tabela 4 - Número Mais Provável de coliformes termotolerantes no leite cru refrigerado, das propriedades analisadas

\begin{tabular}{ccc}
\hline & \multicolumn{2}{c}{ Coliformes termotolerantes $\left(\mathbf{N M P . m L} \mathbf{~}^{\mathbf{1}}\right)$} \\
\cline { 2 - 3 } Coleta & Ordenha Mecânica & Ordenha Manual \\
\hline 1 & ausente & ausente \\
2 & $9,3.10^{2}$ & $2,3.10^{2}$ \\
3 & $1,1.10^{4}$ & $4,3.10^{2}$ \\
4 & $9,3.10^{2}$ & ausente \\
5 & $2,4.10^{3}$ & ausente \\
& \multicolumn{3}{c}{ Não estabelecido } \\
\hline Padrão
\end{tabular}

Citadin et al. (2007), analisando coliformes termotolerantes na região oeste do Paraná, observaram resultados entre $1,6 \times 10^{1}$ a $1,1 \times 10^{4} \mathrm{NMP} \mathrm{mL}^{-1}$. Moraes et al., (2005), também constataram a presença de coliformes termotolerantes em 8 propriedades do Estado do Rio Grande do Sul, sendo que foram analisadas 21 propriedades de ordenha mecânica, ficando evidenciado a deficiência de higiene.

Segundo Arcuri et al. (2008), todos os produtores deveriam se esforçar ao máximo para a melhoria das condições higiênicas durante a ordenha, a fim de reduzir os níveis de contaminação microbiana e atender os padrões exigidos pela legislação.

\section{Conclusão}

Em todas as amostras analisadas quanto à presença de mesófilos e psicrotróficos, os valores se mantiveram dentro do permitido pela legislação. Por outro lado, mesmo ainda não havendo padrão pela legislação, apresentou contagens insatisfatórias para coliformes totais e termotolerantes, especialmente na propriedade com ordenha mecânica. Assim, os procedimentos de higiene e limpeza por parte dos colaboradores poderiam ser aplicados com mais rigor.

\section{Agradecimentos}

Os autores agradecem a Universidade do Estado de Minas Gerais e os proprietários das propriedades avaliadas, pelo desenvolvimento deste trabalho. 


\begin{abstract}
The objective of this study was to evaluate the quality of refrigerated raw milk obtained from rural properties of Frutal/MG, with two types of milking (mechanical and manual). Aerobic mesophilic, psychrotrophic and total coliforms and thermotolerant were analyzed. For the mesophilic aerobic microorganisms, the results ranged from $7.9 \times 10^{3}$ to $2.2 \times 10^{5} \mathrm{CFU} \mathrm{mL}^{-1}$ (manual milking), and between $7.9 \times 10^{3}$ to $6.4 \times 10^{4} \mathrm{CFU} \mathrm{mL}^{-1}$ (mechanical milking). In the psychrotrophic count, only in the first collect of milk from the mechanical milking had this kind of microorganism, with a value of $1.85 \times 10^{2} \mathrm{CFU} \mathrm{mL}^{-1}$, while in the manual milking had scores in the first and last collection, ranging from $2.5 \times 10^{2}$ to $1.3 \times 10^{3} \mathrm{CFU} \mathrm{mL}^{-1}$. Regarding the presence of coliforms, were found higher counts on the property of mechanical milking, which was the presence of total coliforms in

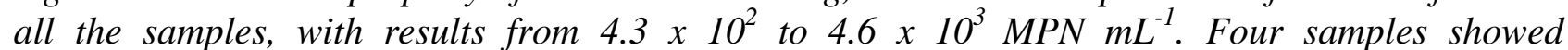
thermotolerant coliforms, ranging from $9.3 \times 10^{2}$ to $1.1 \times 10^{4} \mathrm{MPN} \mathrm{mL}^{-1}$. In the property with manual milking, there was the presence of total coliforms in two samples, with values from $9.2 x$ $10^{1}$ to $4.6 \times 10^{3} \mathrm{MPN} \mathrm{mL}^{-1}$, which also showed thermotolerant coliforms, with counts between

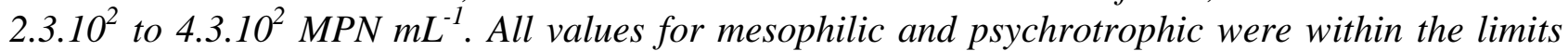
required by legislation. For the coliforms, although there is no established standard for raw refrigerated milk, high counts may indicate deficiencies in hygiene practices during the milking.
\end{abstract}

Key - words: Microbiological quality; raw refrigerated milk; mechanical milking; manual milking

\title{
Referências
}

APHA. American Public Health Association. Compendium of Methods for the Microbiological Examination of Foods. 3 ed. Washington: APHA, p. 325-369, 1992.

ARCURI, E. F. Qualidade microbiológica do leite refrigerado nas fazendas. Arquivo Brasileira de Medicina Veterinária e Zootecnia, v. 58, n. 3. p. 440-446, 2006. http://dx.doi.org/10.1590/S0102-09352006000300024

ARCURI, E. F.; SILVA, P. D. L.; BRITO, M. A. V. P.; BRITO, J. R. F.; LANGE, C. C.; MAGALHÃES, M. M. A.. Contagem, isolamento e caracterização de bactérias psicrotróficas contaminantes de leite cru refrigerado. Ciência Rural, v. 38, n. 8, p. 2250-2255, nov. 2008. http://dx.doi.org/10.1590/S0103-84782008000800025

BRASIL. Ministério da Agricultura, Pecuária e Abastecimento. Departamento de Inspeção de Produtos de Origem Animal. Instrução Normativa no 51, de 18 de setembro de 2002. Coleta de leite cru refrigerado e seu transporte a granel. Diário Oficial da República Federativa do Brasil, n. 172, p. 8-13, 20 set. 2002a. Seção I.

CERQUEIRA, M. M. O. P.; LEITE, M. O. Doenças transmissíveis pelo leite e derivados. Cadernos Técnicos da Escola de Veterinária da UFMG, n. 13, p. 39-62, 1995.

CITADIN, A. S.; POZZA, M. S. S.; POZZA, P. C.; NUNES, R. V.; BORSATTI, L.; MANGONI, J. Qualidade microbiológica do leite cru refrigerado e fatores associados. Revista Brasileira de Saúde e Produção Animal, v. 10, n. 1, p. 52-59, 2009.

EMPRESA BRASILEIRA DE TECNOLOGIA AGROPECUÁRIA, disponível em <http://www.cnpgl.embrapa.br/nova/informacoes/estatisticas/producao/tabela0230.php>. Acesso em: 17 Ago. 2011.

FRANCO, B. D. G. M.; LANDGRAF, M.. Microbiologia dos alimentos. São Paulo, Atheneu, 2008.

MORAES, C. R.; FUENTEFRIA, A. M.; ZAFFARI, C. B.; CONTE, M.; ROCHA, J. P. A. V.; SPANAMBERG, A.; VALENTE, P.; CORÇÃO, G.; COSTA, M.. Qualidade microbiológica do leite cru produzido em cinco municípios do Estado do Rio Grande do Sul, Brasil. Acta Scientiae Veterinariae, v. 33 n. 3, p. 259-264, 2005.

MÜLLER, E. E. Qualidade do leite, Células Somáticas e prevenção da mastite. In: SIMPÓSIO SOBRE SUSTENTABILIDADE DA PECUÁRIA LEITEIRA NA REGIÃO SUL DO BRASIL. Maringá: UEM, p. 206-217, 2002. 
NERO, L. A.; VIÇOSA, G. N.; PEREIRA, F. E. V.. Qualidade microbiológica do leite determinada por características de produção. Ciência e Tecnologia de Alimentos, v. 29, n. 2, p. 386-390, 2009. http://dx.doi.org/10.1590/S010120612009000200024

PINTO, C. L. O.; MARTINS, M. L.; VANETTI, M. C. D.. Qualidade microbiológica do leite cru refrigerado e isolamento de bactérias psicrotróficas proteolíticas. Ciência e Tecnologia de Alimentos, v. 26, n. 3, p. 645-651, 2006. http://dx.doi.org/10.1590/S0101-20612006000300025

RIBEIRO, M. E. R.; STUMPF JÚNIOR, W.; GOMES, J. F.; BITTENCOURT, D; BARCELOS, P.; BARBOSA, R. S.; ZONTA, M.; AQUINO, S. L. G.; CÂNDIA, P. R.; DALBANN, P. R.. Sistema de coleta e envio de amostras de leite para determinação dos componentes do leite, contagem de células somáticas e contagem bacteriana total. Pelotas: Embrapa Clima Temperado, 2007, disponível em <http://www.cpact.embrapa.br/publicacoes/download/documentos/documento_206.pdf>. Acesso em 02 Out. 2011.

SANTANA, E. H. V.; BElOti, V.; BARROS, M. A. F., MORAES, L. B.; GUSMÃO, V. V.; PEREIRA, M. P.. Contaminação do leite em diferentes pontos do processo de produção: I. Microrganismos aeróbios mesófilos e psicrotróficos. Semina: Ciências Agrárias, v. 22, n.2, p. 145-154, 2001.

SANTOS, M. V.. Diagnóstico da qualidade microbiológica do leite em fazendas leiteiras, 2008, disponível em <http://www.milkpoint.com.br/artigos-tecnicos/qualidade-do-leite/diagnostico-da-qualidade-microbiologica-do-leiteem-fazendas-leiteiras-34084n.aspx>. Acesso em 12 Jul. 2011.

SEBRAE/FAEMG. Diagnóstico da Pecuária Leiteira do Estado de Minas Gerais em 2005: relatório de pesquisa Belo Horizonte: FAEMG, 2006.

SILVA, M. A. P.; SANTOS, P. A.; SILVA, J. W.; LEÃO, K. M.; OLIVEIRA, A. N.; NICOLAU, E. S.. Variação da qualidade do leite cru refrigerado em função do período do ano e do tipo de ordenha. Revista Instituto Adolfo Lutz, v. 69, n. 1, 2010a.

SILVA, M. R.; SACANAVACCA, J.; GRANDA, T. K. V.; SEIXAS, F. A. V.; GRANDA, E. À.. Avaliação higiênicosanitária do leite produzido em Umuarama (Paraná). Boletim do Centro de Pesquisa de Processamento de Alimentos, v. 28, n. 2, p. 271-280, 2010b.

SILVA, L. C. C.; BELOTI, V.; TAMANINI, R.; d'OVIDIO, L.; MATTOS, M. R.; ARRUDA, A M. C. T.; PIRES, E. M. F.. Rastreamento de Fontes da Contaminação Microbiológica do leite cru durante a ordenha em propriedades leiteiras do Agreste Pernambucano. Semina: Ciências Agrárias, v. 32, n. 1, p. 267-276, 2011.

SILVEIRA, I. A.; CARVALHO, E. P.; TEIXEIRA, D.. Influência de micro-organismos psicotróficos sobre a qualidade do leite refrigerado. Revista Higiene Alimentar, v. 12, n. 55, p. 21-26, 1998.

TAMANiNI, R.; SILVA, L. C. C.; MONTEIRO, A. A.; MAGNANI, D. F.; BARROS, M. A. F.B.; BELOTI, V.. Avaliação da qualidade microbiológica e dos parâmetros enzimáticos da pasteurização do leite tipo "C" produzido na região norte do Paraná. Ciências Agrárias, v. 28, n. 3, p. 449-454, 2007.

VINHOLIS, M. M. B.. Economia de escala no processo de resfriamento do leite cru tipo B em propriedades rurais. In: XLV Congresso da Sociedade Brasileira de Economia, Administração e Sociolgia Rural, Embrapa Pecuária Sudeste, São Carlos, São Paulo, Brasil, 2007.

Submetido em 07 dez. 2011, Aceito para publicação em 26 dez. 2012. 